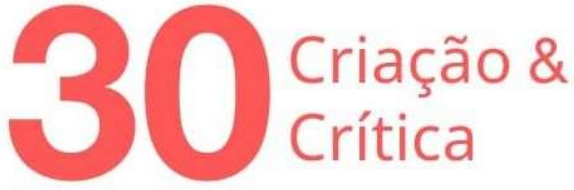

\section{INCIDENTES POÉTICOS DE ADÍLIA LOPES, LEITORA DE BARTHES 1}

Paulo Alberto da Silva Sales ${ }^{2}$

Resumo: Pretende-se desenvolver uma leitura da poesia de Adília Lopes por meio da perspectiva da escrita de incidentes em que Barthes trata da essência do romanesco: o fragmento. Por meio da criação de uma poesia biografemática, as últimas publicações da poeta portuguesa têm evidenciado a construção de um sujeito pela escrita, assim como Barthes o fez, sobretudo em Incidentes (2004b) e em Roland Barthes por Roland Barthes (2003). Observa-se que os poemas pertencentes às últimas obras de Adília se valem da abordagem de traços de vida insignificantes, que são retomados pelas sensações do corpo. Conclui-se que os incidentes poéticos adilianos proporcionam aos leitores que se identifiquem com a poeta - à maneira barthesiana do desejo de escrever a leitura - por meio de recordações da infância presentes nas sensações auditivas, gustativas e táteis.

PALAVRAS-CHAVE: Adília Lopes e Roland Barthes, biografema, incidentes, infância, sensações.

\section{POETIC INCIDENTS OF ADÍLIA LOPES, BARTHES' READER}

ABSTRACT: It is intended to develop a reading of Adília Lopes' poetry through the perspective of the writing of incidents in which Barthes deals with the romance essence: the fragment. By the creation of a biographematic poetry, the latest publications of the Portuguese poet have evidenced a construction of a subject through writing as well as Barthes did in Incidentes (2004b) and Roland Barthes por Roland Barthes (2003). Note that the poems belonging to the last works of Adilia avail of the approach of insignificant traces of life that are retaken by the body sensations. It is concluded that Adília's poetic incidents provide readers with the identification with herself - according to the Barthesian desire to describe the reading - by the childhood reminiscences present in hearing, tactile and taste sensations.

KEYWORDS: Adília Lopes and Roland Barthes, biographeme, incidents, childhood, sensations.

\section{Il faut oser. Oser aimer.}

Roland Barthes in Playboy, Setembro 1977 (in Roland Barthes, Le grain de la voix: entretiens 1962-1980, Paris, Seuil, 1981, p. 284)

(LOPES, 2016b, p. 8)

\footnotetext{
${ }^{1}$ Este estudo está vinculado à pesquisa de Pós-Doutorado que estamos desenvolvendo na Universidade Federal Fluminense (2021-2022) a respeito da poética de Adília Lopes, sob supervisão da Profa. Dra. Ida Alves e co-supervisão da Profa. Dra. Celia Pedrosa.

2Professor de Linguagens no Instituto Federal Goiano - Campus Hidrolândia/IF Goiano, Hidrolândia, Goiás, Brasil, e do Programa de Pós-Graduação Stricto Sensu em Língua, Literatura e Interculturalidade da Universidade Estadual de Goiás - Campus Cora Coralina/UEG, Cidade de Goiás, Goiás, Brasil. E-mail: paulo.alberto@ifgoiano.edu.br.
} 


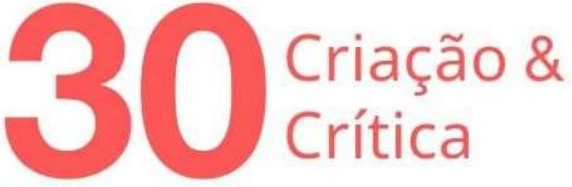

\section{Introdução}

Os leitores da poesia de Adília Lopes estão acostumados a se depararem com poemas infinitamente remissivos, cuja tessitura de suas criações revelam o emprego de níveis intertextuais diversos, que vão desde o deslocamento de citações de nomes, versos, trechos de obras da tradição até a apropriação de discursos da cultura em geral. Neles, podem ser lidas as textualidades apropriadas de formas distintas em um outro lugar, bem como a poeta promove uma reflexão sobre a sua própria textualidade. Desde a publicação de seus primeiros livros, datados da década de 1980 até os dois decênios do século XXI, percebe-se que Adília apresenta uma "poesia não-original" e feita por meio da prática da citacionalidade (PERLOFF, 2013) que entrecruza discursos de fontes diversas, o que tem tornado seus poemas altamente híbridos. Em sua poética, é possível delinear traços bem característicos, os quais se apresentam por meio de discursos rememorativos de textos lidos e de histórias vividas/ ouvidas pela poeta que são interrelacionados à apropriação de nomes, de textos e de discursos de outrem: "Aqui não é singing in the rain. Preferem morrer num/ acidente a largar o guarda-chuva" (LOPES, 2016b, p. 25). Adília, ao "escrever sem escrever" (VILLA-FORTE, 2019) promove associações de textualidades oriundas de espaços e de tempos distintos em sua escrita momentânea, o que torna seus textos inespecíficos:

O meu quarto é igual

ao camarim da Marlene Dietrich

em Marrocos de Joseph von Sternberg

\author{
O meu quarto o que é? \\ não é Petrogrado 1915 Malevitch o quadrado negro \\ é o cubo a esfera cor-de-rosa de Adília Lopes \\ o pêndulo radiestético do Prof. Girassol \\ não andamos longe de Petrogrado \\ afinal de contas
}

(LOPES, 2016b, p. 18-19)

Em seus mais recentes livros, sobretudo em Manhã (2015), Bandolim (2016a), Z/S (2016b), Estar em casa (2018) e Dias e Dias (2020), há um processo de ficcionalização do autobiográfico na poesia - por meio da inserção de memórias, de fatos e de fotografias de Adília em diversos momentos de sua vida - que, por sua vez, tornam porosos os limites entre vida e experiência. Associada à essa estratégia, a poeta portuguesa amplia ainda mais o repertório discursivo das memórias de leituras, que extrapolam o campo do puramente artístico e literário, e passam a dialogar com 


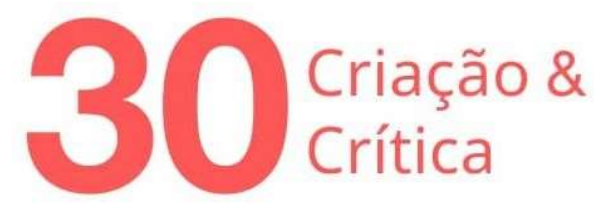

questões da teoria literária, além de aspectos das ciências humanas, das ciências biológicas e até mesmo da física quântica e da análise combinatória da matemática. Sobretudo nas obras Manhã, Bandolim, Z/S e Estar em Casa, a poeta faz intertextualidade direta com o pensamento e com a escrita de Roland Barthes, sobretudo relacionada à dicção de Barthes em suas obras Incidentes (2004b) e em Roland Barthes por Roland Barthes (2003), nas quais se notam indícios do projeto de escrita romanesca do semiólogo francês.

Nesses últimos livros de Adília, os leitores se deparam com pequenas narrativas líricas que, veremos, reverberam pequenos "incidentes" de escrita poética: elas podem ser lidas, ao mesmo tempo, tanto como poemas em prosa quanto pequenas anotações e/ou fragmentos de um "diário" nos quais se colocam em evidência a essência do romanesco, tal como Barthes entendia os incidentes. $O$ intenso corpo a corpo com o pensamento do autor de Critique et Vérité - que se materializa no texto poético sob a perspectiva dos biografemas e dos incidentes -, levou Adília a dedicar o livro Z/S, de 2016, a Barthes, cuja intertextualidade direta presente no título claramente evidencia o jogo com as letras de $S / Z$ (1999), livro, esse, no qual Barthes se dedica ao estudo da narrativa Sarrazine, de Balzac. Em Z/S, há um poema interessante que ressalta o processo de apropriação de textualidades diversas - que lembram os textes scriptibles (abertos e plurais) - registradas pelos vestígios corpóreos do sujeito ficcionalizado pela escrita. Eis o poema:

\section{KAGEMUSHA}

No ano em que Kagemusha de Akira Kurosawa estreiou em Lisboa, eu estudava métodos matemáticos da física. Tinha de saber os integrais de Lebesgue. Os integrais de Lebesgue faziam-me lembrar a «sympathie tardive pour les lesbiennes» de Fourier de que fala Barthes. Tinha de estudar as transformadas de Fourier, essas estranhas mulheres. Este Fourier das transformadas não é o Fourier dos falanstérios. $8 / 12 / 15$

(LOPES, 2016b, p. 20)

Como se nota nesse poema, ao se apropriar de leituras diversas, a poeta se constrói por meio de uma escrita biografemática que põe em movimento textualidades deslocadas de seus contextos. Veremos como Adília, a partir da perspectiva em que Barthes reflete sobre aescrita biografemática e feita por meio de incidentes, ficcionalizase em suas micronarrativas líricas. Primeiramente, vejamos como tais incidentes foram pensados por Barthes, autor, esse, comquema poeta dialoga intensamente. 


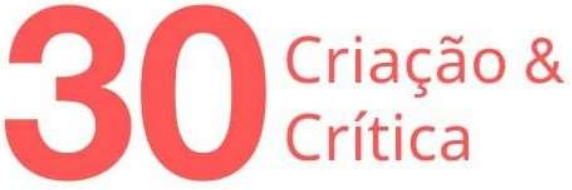

\section{Incidentes de Barthes}

« Tout ceci doit être considéré comme dit par un personnage du roman ». [Tudo isto deve ser considerado como dito por uma personagem de romance]: Anuncia-nos a voz narrativa de Roland Barthes por Roland Barthes (2003) na primeira página do livro, cuja escrita do eu barthesiano se entrelaça aos estilhaços de memória, às fotografias do escritor e às teorias relacionadas ao prazer da escritura. Tendo decretado a morte do autor em 1968, Barthes faz esse espectro autoral ressurgir na escritura por meio de lembranças do que ele teria sido. No pensamento do "nouveau critique", em diálogo com a noção de "função" autoral apresentada por Foucault (2006), há uma inversão no papel do retorno do autor "[...] que agora não tem uma existência prévia ao livro, mas posterior. [...] [constata-se] a impressão de que não há verdade anterior à obra, [e] que toda verdade deve ser construída, posteriormente, pelo leitor" (PINO, 2016, p. 18). Esse novo autor espectral aparece por meio de "restos" do que ele foi e que, de alguma forma, ainda continua vivo. A escritura feita a partir dos resquícios desse sujeito nos leva a pensar a vida por meio da jouissance, ou seja, da possibilidade do eu se fabular no papel por outros meios, sejam eles projetados a partir de histórias tomadas pelas margens da existência do sujeito. Nessa perspectiva, sai de cena o autor da vida para a ascensão do ator no texto. Na sua Preparação do romance I: da vida à obra (2005a), o semiólogo francês entende que a reinvestida no componente biográfico, em seu projeto de escrita romanesca, deve flertar com o desejo da escritura. Trata-se, talvez, do "[...] querer escrever algo $\rightarrow$ Querer-Escrever + Objeto. Haveria fantasias de escritura: tomar a expressão em sua força desejante. [...] Um enredo com um sujeito (eu) e um objeto típico (uma parte do corpo, uma prática, uma situação)" (BARTHES, 2005a, p. 20). Essa fantasia de escritura barthesiana dá-se por meio desse eu que produz o objeto literário, escrevendo-o. Isso se realiza por meio de rememorações e lampejos romanescos em atos eróticos pelos quais se deixam envolver a mão que escreve:

Eis-me aqui, para começar, algumas imagens: elas são a cota de prazer que o autor oferece a si mesmo, ao terminar seu livro. [...] Não se encontrarão pois aqui, mescladas ao romance familiar, mais do que as figurações de uma pré-história do corpo - desse corpo que se encaminha para o trabalho, para o gozo da escritura. Pois tal é o sentido teórico dessa limitação: manifestar que o tempo da narrativa (da imageria) termina com a juventude do sujeito: não há biografia a não ser a da vida improdutiva. Desde que produzo, desde que escrevo, é o próprio Texto que me despoja (felizmente) de minha duração narrativa. O texto nada pode contar; ele carrega meu corpo para outra parte, para longe da minha pessoa imaginária, em direção de uma espécie de língua sem memória que já é a do Povo, da massa 


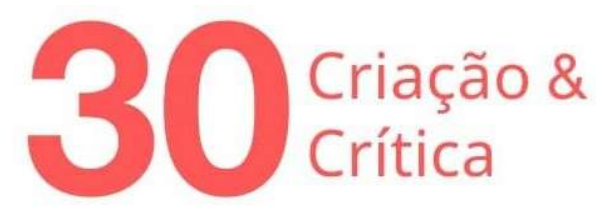

insubjetiva (ou do sujeito generalizado), mesmo se dela ainda estou separado pormeumododeescrever (BARTHES, 2003, p. 14, grifos nossos).

Essas figurações da pré-história do corpo, a que Barthes se refere, e cujos trabalhos se encaminham para o gozo da escritura assumem uma nova posição diante dos signos que envolvem a vida. Poder-se-iam lê-las como fiç̧ões-críticas em que há a construção do sujeito por meio da escrita permeada pelos componentes biográficos: as "verdades", criadas nesses escritos, ganham novos e imprecisos contornos por meio de uma poética não do eu, mas, sim, segundo Claudia Pino (2016) ${ }^{3}$, do corpo. O retorno desse corpo na escrita se materializa por meio da noção de biografema que Barthes desenvolve no prefácio de Sade, Fourier, Loyola (2005b). Ao se deter no exame dos prazeres da escritura, Barthes entende que esses três autores são fundadores de línguas novas pelas quais seria possível isolar-se (surgir de um vazio material), articular-se (cortar, combinar, ajustar e produzir regras de junção) e ordenarse (submeter os signos a grande sequência erótica). Por essas razões, os três epígonos estudados por Barthes são "formuladores" que, na verdade, criam uma língua nova por meio de uma quarta operação: a teatralização. Os prazeres que os leitores compartilham dos textos desses autores se realizam de maneira mais aguda "[...] quando o texto "literário" (o Livro) transmigra para dentro de nossa vida, quando outra escritura (a escritura do Outro) chega a escrever fragmentos da nossa própria cotidianidade, enfim, quando se produz uma co-existência" (BARTHES, 2005b, p. xiv$\mathrm{xv}$ ). Partindo desse pressuposto performativo, o autor que retorna no texto não é o autor histórico, biológico, civil, mas sim percepções do corpo que evidenciam "plurais de encantos" e "pormenores tênues".

Por meio dessa construção espectral, motivada pelo prazer do texto barthesiano, é que podemos ler os biografemas, cuja base se estrutura pela lógica da fragmentação e dos acontecimentos. Por ser invadida por imprecisões e repetições, a retomada de elementos da vida passa a ser direcionada pela desrazão e por traços de encontros. Fala-se do outro em mim e de mim do outro, resultando, como quer Lacan, no outramento: "[...] involutiva [é a] escritura nesse jogo de invenção e de destruição de si e do outro. O biografema faz daquele que lê e escreve uma vida o próprio dramaturgo desta vida" (COSTA, 2011, p. 13). Essa escrita teatralizada de si comporta "traços de vida insignificantes" (PINO, 2016) por meio de cantos descontínuos e nos quais se testemunham detalhes, lembranças e traços da vida enquanto potência movimentada unicamente pelo prazer: "Meu corpo só está livre de todo o imaginário quando reencontra o espaço de trabalho. Esse espaço é, em toda

\footnotetext{
${ }^{3}$ Ver De um corpo para outro: Roland Barthes e a biografemática, de Claudia Amigo Pino (2016), em que há a exegese da construção do biografema barthesiano a partir das sensações corpóreas, sobretudo relacionadas à audição, ao paladar e ao tato. Baseamo-nos nessa perspectiva para ler a recente poesia adiliana, em que há uma inclinação para a construção de biografemas relacionados, na grande maioria, à infância, que é revisitada por meio das sensações gustativas e auditivas.
} 


\section{$30 \begin{gathered}\text { criaça \& \& } \\ \text { critica }\end{gathered}$}

parte, o mesmo, pacientemente adaptado ao prazer de pintar, de escrever, de classificar" (BARTHES, 2003, p. 50).

Essa perspectiva de criação ficcional do sujeito por meio de traços de vida insignificantes - perceptíveis por meio de novas abordagens do corpo - são verificadas na rememoração dos sentidos, sobretudo relacionados às sensações gustativas, auditivas e táteis. Sob essa ótica de leitura, Pino reforça que esse novo autor, ou melhor, esses restos corpóreos espectrais do sujeito autoral estabelecem uma convivência: se há um corpo morto, quem o revive - por meio dos sentidos - é o leitor. Logo, o biografema se materializa por meio daquilo que foi o autor e que, por sua vez, se dispersou e se disseminou nos atos de leitura. Ao invés de se apegar à cronologia, os biografemas se veem enamorados de "[...] séries disjuntivas, fragmentos, paradoxos, efeito[s], superfícies, a-historicidade, acontecimentos, esquecimento, do que é errante e fugidio" (COSTA, 2011, p. 12). Para exemplificarmos como a construção biografemática do sujeito é mediada pelos prazeres relacionados ao corpo e, sobretudo, por meio de sentidos, nos apropriamos de uma passagem de $R B$ por $R B$ em que se percebe a ficcionalização do escritor por meio de fragmentos que são articulados a fotografias do autor registradas nos primeiros anos de vida:

Figura 1 - Página 34 e 35 do livro Roland Barthes por Roland Barthes

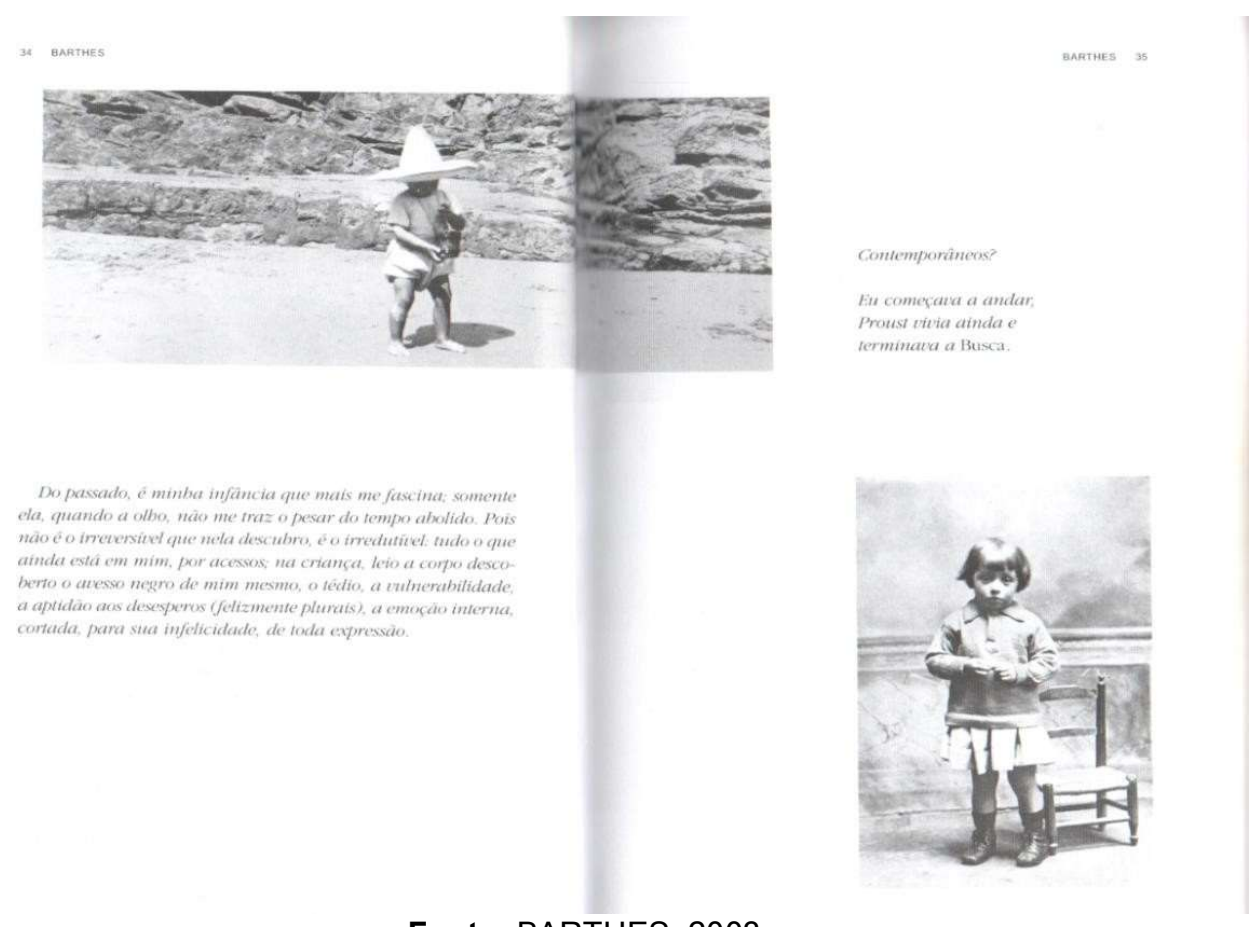

Fonte: BARTHES, 2003. 


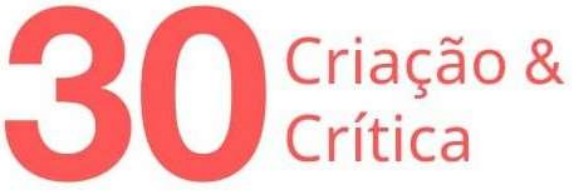

Nessas passagens, nota-se a tentativa biografemática de registrar sensações em um corpo que escreve movido por desejos rememorados da infância: "Do passado, é a minha infância que mais me fascina; [...] tudo o que ainda está em mim, por acessos; na criança, leio a corpo descoberto o avesso negro de mim mesmo, o tédio, a vulnerabilidade, a aptidão dos desesperos (felizmente plurais)". Esse sujeito se circunscreve textualmente por meio do resgate de percepções sensoriais - os primeiros prazeres gustativos, visuais, táteis, auditivos - que o marcaram na infância. As fotografias evidenciam essas sensações - brincadeiras, olhares, gostos - muito embora Barthes (2004c) entenda que a fotografia não é uma língua e ela não trabalhe com pedaços de material. Contudo, a serviço do texto biografemático, as imagens reafirmam as "insignificâncias" revitalizadas - a lembrança dos odores do bairro antigo - com as quais o sujeito se reconstrói. São flashes, gestos, lembranças, ou melhor, "incidentes" que o corpo biografemático experienciou: "A delícia daquelas manhãs de sol em U.: o sol, a casa, as rosas, o silêncio, a música, o café, o trabalho, a quietude insexual, a vacância das agressões..." (BARTHES, 2003, p. 38). Em "A luz do sudoeste", publicado primeiramente em L'humanité, em 17/07/1977 e, depois, incluído nos Incidentes (2004b), Barthes trata dessas percepções auditivas (sotaques que marcam a primeira infância), visuais (uma linha imagética que a criança internalizou por meio das constantes viagens de automóvel) e táteis (ao comprar charutos em suas férias na cidade de Bayonne). Esses traços de vida insignificantes - os cheiros e o sabor do chocolate, o azeite espanhol, o ar confinado das lojas escuras e das ruas estreitas, o papel envelhecido do livro da biblioteca - são descritos e compartilhados com o leitor que dá vida a esse corpo biografemático em recordações:

[...] só tomei das "grandes realidades" a sensação que elas me proporcionavam: odores, fadigas, sons de vozes, andanças, luzes, tudo aquilo que, de algum modo, é irresponsável pelo real e não tem outro sentido senão o de formar mais tarde a lembrança do tempo perdido (bem diferente foi minha infância parisiense: cheia de dificuldades materiais, ela teve, por assim dizer, a abstração severa da pobreza e, da Paris dessa época, quase não tenho "impressões") (BARTHES, 2004b, p. 8-9).

Nota-se que a escrita fragmentária desses incidentes é inscrita no ímpeto de captar as grandes realidades mediadas pelos prazeres através de sensações do corpo. Ao interagirem com os biografemas, os leitores se identificam com as sensações desse corpo e também as sentem, ou ainda, passam a ter os mesmos desejos que o autor teve quando as escreveu. Tanto nos diversos fragmentos que compõem $R B$ por RB quanto nos Incidentes - obra póstuma publicada em 1987 - que engloba anotações de coisas vistas e ouvidas na viagem que Barthes fez a Tânger e 


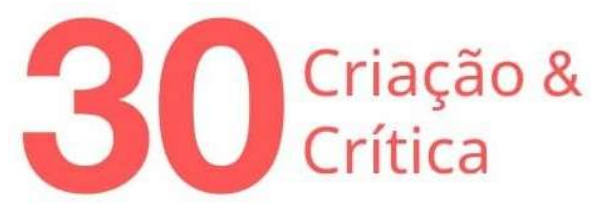

a Rabat, no Marrocos ${ }^{4}$, e depois no Sul, em 1968 e 1969, encontramos o mundo barthesiano experimentado não em forma de objetos, mas, sim, através de uma escrita pulsante que tenta se apossar do imediato. Nesses escritos, aparentemente desconexos e díspares, há o jogo de escritura: o ler-escrever movido pelas descobertas de prazeres diários. A colocação da escrita em forma de incidentes, ou seja, por meio de fendas insignificantes em grandes superfícies vazias, experimentam formas breves e análogas ao haicai japonês. Esses incidentes - literalmente escritos que caem sobre alguma coisa - poderiam vir a compor o projeto de romance Vita nova que, até onde se sabe, não foi concluído ${ }^{5}$. François Wahl, amigo de Barthes e editor da obra Incidents, esclarece que se tratam de fragmentos, apenas. Neles, não há uma interpretação de Barthes sobre o Marrocos, mas, sim, "[...] a colocação da escrita de encontros - de incidentes - que poderiam ter constituído a trama de um romance, desde que subtraídos todos os caracteres ou personalidades constituídas: trechos de romance sem suportes pessoais" (WAHL, 2004, p. viii-ix). Tais minitextos condensam a própria essência do romanesco - o querer-escrever - esboçadas em Preparação do romance e n'O prazer do texto. Tratam-se de "[...] linhas teimosas que não gostam dasideias nem do exame e sorriem, esquivam-se tanto do diário transbordante de subjetividade quanto da literatura cheia de sentido, preferindo o papel branco" (OLIVEIRA, 2010, p. 171). Eis alguns desses incidentes de Barthes:

Em cada tarde de Ramadã, por volta das cinco horas (estamos em novembro), o restaurante da Libération, na medina, visto da rua, é transformado em asilo com longas mesas alinhadas, ladeadas de homens sentados bem juntos, comendo sopa; o único garçom costumeiro está atarefado, como um irmão converso.

Naciri sabe bem a língua francesa; prova disso é que ele insere nela, com desenvoltura, sintagmas estrangeiros: "Eles tiveram de sair esta tarde, because Ramadan."

\footnotetext{
"Tais informações aparecem na "Nota do editor francês" que abre a edição de Incidentes (WHAL, 2004, p. viii).

${ }^{5} \mathrm{Em}$ Roland Barthes: a aventura do romance, de Claudia Amigo Pino (2015), há a pesquisa sobre a aventura crítica de se entrar no universo criativo de Barthes. Especificamente no tópico "Escrever a vida", Pino consente que desde os primeiros escritos do semiólogo, as ideias sobre a escrita da vida tomaram caminhos distintos. Contudo, esses caminhos se entrecruzaram no projeto de romance de Barthes: "[...] Vita nova, o romance com a vida no título, encontra o caminho de Gide nos diversos diários que o compõem ou dialogam com o projeto: Diário de luto, "Incidentes", "Deliberação", "Noite em Paris", além de outras tentativas diarísticas que hoje ainda encontram-se no âmbito privado. Esse romance, porém, como anunciado na conferência inaugural do curso, "Durante muito tempo, fui dormir cedo", era uma reescritura da obra de Proust, autor abertamente contra a escrita cotidiana e que defendia que a literatura só era possível a partir do distanciamento da vida". (PINO, 2015, p. 23)
} 


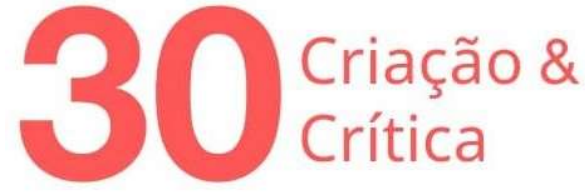

\begin{abstract}
$\star * *$
O "chefe da contabilidade" (adolescente de rosto gracioso) enuncia com gravidade: a civilização é quando se conhecem os próprios direitos e se está consciente dos deveres. Depois disso, acompanhando-nos, ele cai na gargalhada.
\end{abstract}

Nesta sexta-feira, na hora da tarde em que o Ramadã terminou, foi preciso continuar sem fumar, porque, ao passar da rua para uma casa judia, o sabá estava começando.

Professores de francês: discutem um projeto de doutorado: quais serão as provas pedagógicas? Embaraço, confusão. De repente, para um grande alívio de todos, um exclama: A lição! (de agregação)

(BARTHES, 2004b, p. 34-35).

Nos fragmentos, é perceptível como Barthes capta as realidades por meio dos sentidos: vigilante às vidas, aos espaços públicos e às textualidades que o circundam, ele passa a anotar as sensações que tais ocorrênciasreverberam em si. Sob essa mesma perspectiva, a de que os incidentes chegam, muitas das vezes, ao sujeito sem que ele esteja alerta, bem como à escrita biografemática que dialoga com os espaços textuais diversos, podemos apresentar uma leitura produtiva da obra poética da portuguesa Adília Lopes. Embora a autora lusitana tenha apresentado diálogos diretos com a escrita e com o pensamento barthesiano desde sua primeira publicação, Um jogo bastante perigoso, de $1985^{6}$, verifica-se, precisamente, os ideais do autor de S/Z nas configuração das obras Manhã (2015), Bandolim (2016a), Z/S (2016b), Estar em casa (2018) e Dias e Dias (2020) em que a poeta, tal como realizado em $R B$ por $R B$ e nos Incidentes, prima emconstruir um sujeito por meio da escrita. São textos que, muito embora pertençam ao universo da poesia lírica, dialogam com as anotações, com os registros cotidianos e com os escritos das "Noites de Paris", datados de 27 de agosto a 15 de setembro de 1979: trata-se, na sua grande maioria, de pequenas micronarrativas líricas nas quais a autora - Adília Lopes - se constrói por meio de biografemas que registram, assim como Barthes, as sensações da infância7e da adolescência. Atreladas a essas rememorações sensoriais do corpo escrito, são grafados inúmeros incidentes, tais

\footnotetext{
${ }^{6}$ Integrada à obra Dobra (2014).

${ }^{7}$ Rosa Maria Martelo (2017) apresenta um estudo sobre a presença da memória infantil na poesia de Adília, muito embora ela se detenha, na sua grande maioria, aos poemas reunidos em Dobra. Há menções há a obra Manhã, mas a crítica portuguesa não se detém às últimas obras adilianas.
} 


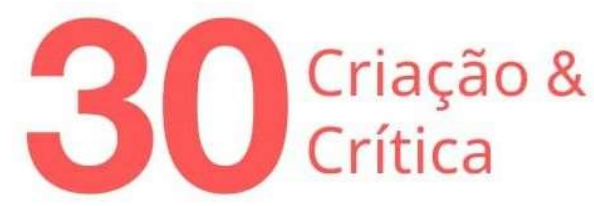

como trechos de leituras de obras diversas que são postas em movimento, registros de fatos cotidianos, comentários críticos sobre a vida da personagem no espaço da casa, registros de falas dos antepassados, indicações de leituras de obras canônicase da cultura de massa, cópias literais de trechos de outras obras literárias, bem comode escritos em forma de trocadilhos. Vejamos, então, como as últimas obras de Adília rememoram as sensações do corpo nos biografemas que se inscrevem por meio do prazer do querer-escrever.

\section{Incidentes de Adília}

A presença de Barthes na poesia de Adília se materializa de diversas formas. Há desde registros intertextuais explícitos - "Barthes escreveu já não sei onde cito de cor: o/ açúcar é violento. Acho que tem razão (LOPES, 2015, p. 94)" - à própria criação de poesia a partir da perspectiva biografemática e por incidentes, ou seja, por meio de anotações e de registros colocados como pura essência romanesca, tais como se leem em "Na missa, uma velhota a cantar a ladainha a/ Nossa Senhora em vez de cantar stella matutina/ cantava estrela na cortina. Acho isto lindo. (LOPES, 2015, p. 50) e em "Detesto o paradoxo do gato de Schrödinger./ Gosto do paradoxo de la boîte à Tokyo" (LOPES, 2015, p. 65). Especificamente na obra Manhã, publicada em 2015, nota-se uma construção poética por meio de incidentes, ou seja, escritos que tentam registrar momentos experimentados por meio dos sentidos desse corpo espectral, sobretudo ligados a momentos da infância. Nessa obra, há um total de 102 poemas nos quais o material poético se vale de micro-histórias de conteúdo misto - ligado aos componentes biográficos, intertextuais e metapoéticos - que são rememoradas em diversos momentos da vida desse corpo escrito. Das últimas publicações da poeta, esta é a que mais se aproxima de $R B$ por $R B$. "Colares" é primeiro poema da obra Manhã e, também, pode ser apreendido como um convite aos leitores a compartilharem dos prazeres da poeta em seu ofício rememorativo. Em forma de uma pequena narrativa, ele aposta na construção de imagens que apelam às sensações da, então, criança Adília - ou do que ela pudera ter sido - por meio do tato, da audição e do olhar. Nesse primeiro incidente adiliano, os resquícios corpóreos da poeta se projetam na poesia por meio de uma dicção narrativa fragmentada, que lembra ora a voz de uma criança ora a voz da poeta adulta. Ao fim do poema, Adília interrelaciona uma fotografia sua que, segundo os escritos presentes no fundo da imagem, foi tirada nas festividades de carnaval de 1969: 


\section{0 chisiog}

\section{COLARES}

Em Colares, vi um bulldog branco anão em em cima de uma coluna branca no jardim de uma vivenda. É a minha recordação mais antiga. É estranha. Parece inventada. Mas não é.

Fui com minha avó materna no eléctro da Praia das Maçãs a Sintra. Tudo isto é muito proustiano, é claro.

Quando era muito criança, passava alguns dias de Verão numa pensão em Colares com a minha família. lam os meus pais, a minha avó materna e irmã da minha avó materna.

Na quinta da pensão, vi uma porca deitada no chão a dar de mamar a muitos leitõeszinhos. Adorei.

Em Colares, vi no céu o rasto de um avião a jacto. Pensei que era um raio que ia cair em Lisboa em cima de um armário de que gostava muito. A minha mãe disse-me que não era assim. Há um verso de Rimbaud que me lembra muito esta visão da minha infância mas agora não encontro.

Há cinquenta anos, vi maçãs na Praia das Maçãs trazidas por um riacho ou talvez seja confusão minha.

Lembro-me de andar a passear à noite com os meus pais em Colares pela estrada. A minha mãe dizia-me: "Olha, um pirilampo.» Acho que nunca vi nenhum. Ainda posso ver.

la muitas vezes a Sintra visitar o palácio da vila. O cicerone já me conhecida. Dizia que eu gostava mais de visitar o palácio do que de fazer covinhas na praia. Não era assim. Gostar gostar era da Praia Grande. Fui lá uma vez com minha prima Vera. Fizemos um castelo com um fosso.

(LOPES, 2015, p. 11-12). 


\section{Criação \&}

Figura 2 - Página 13 do livro Manhã

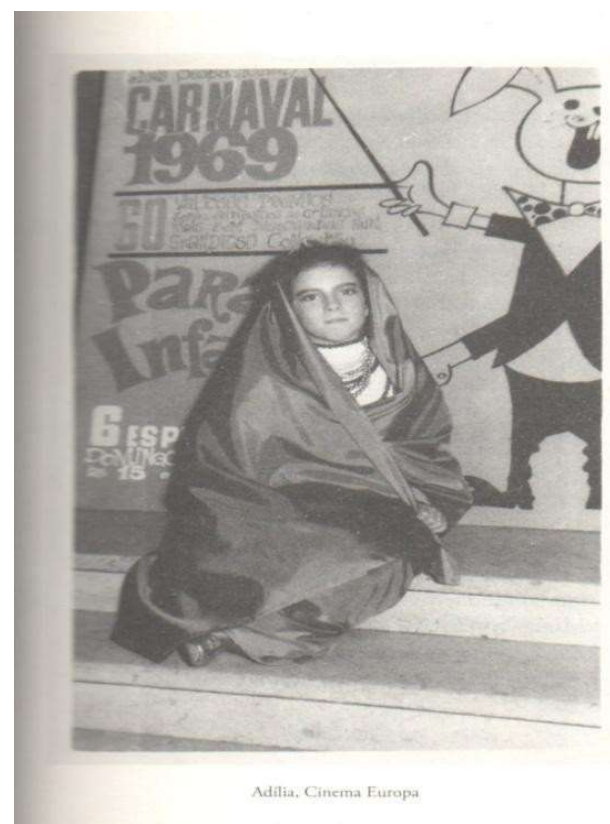

Fonte: LOPES, 2015.

As rememorações por meio dos sentidos (visão, tato, audição) registram uma passagem de Adília por um pequeno vilarejo em Portugal, situado no concelho de Sintra, com pouco menos de 8 mil habitantes. Intertextualmente, tal poema nos remete diretamente às sensações que Barthes tratou em suas estadias no interior do Sul da França e que, por meio delas, conseguiu construir as grandes realidades prazerosas. Ao se reportar ao terceiro Sudoeste, Barthes afirma:

[...] é a cidade onde passei a infância, depois, as minhas férias de adolescente (Bayonne), é a vila para onde volto a cada ano, é o trajeto que une uma e outra e que percorri tantas vezes, para ir comprar na cidade charutos ou artigos de papelaria, ou à estação buscar um amigo. [...] Mas a estrada que prefiro, e cujo prazer me ofereço de propósito, é a que segue a margem direita do Adour; é um antigo caminho de sirga; pontilhado de chácaras e de belas casas. Gosto dele, sem dúvida, por ser natural, essa dosagem de nobreza e de familiaridade que é a própria Sudoeste. [...] Essas insignificâncias são, pois, como portas de entrada dessa vasta região que se ocupam o saber sociológico e a análise política. Nada, por exemplo, tem mais importância na minha lembrança do que os odores daquele bairro antigo, entre Nive e Adour, que se chama pequena Bayonne: todos os objetos do pequeno comércio ali se mesclavam para compor a fragrância inimitável: a corda das sandálias, [...] o chocolate, o azeite 


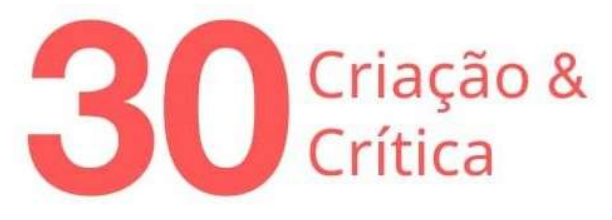

espanhol, o ar confinado das lojas escuras e das ruas estreitas, o papel envelhecido dos livros da biblioteca municipal, tudo isso funcionava como a fórmula química de um comércio que já desapareceu (BARTHES, 2004b, p. 6-9).

Tal como Barthes se reporta aos odores, às formas, às cores e às imagens internalizadas na infância, o poema de Adília também se vale de incidentes ligados à visão que a marcaram profundamente. Na primeira estrofe, um verso chama-nos a atenção: "É minha recordação mais antiga. É estranha. Parece inventada. Mas não é". Aqui, o ato de recordar também é motivado pelo sentido da visão. A criança/poeta internalizou imagens, cheiros e formas em suas idas ao vilarejo lusitano que, por sua vez, a fez relacionar com outras textualidades. Em dois outros dois poemas, intitulados "A padaria" e "Pralines", percebe-se como o biografema é construído por meio das rememorações sensoriais, por meio de cheiros, gostos, formas:

\section{A PADARIA}

Há cinquenta anos, aqui defronte, havia uma padaria. Na montra tinha uma boneca de faiança, da cintura para cima, a comer um pão-de-leite com fiambre. A boneca era muito grande. Estava vestida de cor-de-rosa e branco. Tinha um laço corde-rosa no cabelo. Na padaria, havia também uma balança vermelha.

\section{PRALINES}

No meu bolo de aniversário, mais do que das velas, gostava das pralines. Esferazinhas prateadas sobre a neve, sobre a cobertura de claras em castelo com açúcar.

$18 / 6 / 14$

(LOPES, 2015, p. 15)

Nesses incidentes de poesia, é nítido como a poeta está ligada, sobretudo, às sensações da infância. A escolha intencional do substantivo feminino "manhã" para intitular o livro de 2015, cuja temporalidade remete, simbolicamente, à infância e à adolescência, é reafirmada por inúmeros meios, sejam eles verbais ou não-verbais. Primeiramente, a capa do livro é composta por um tom acinzentado preenchido por inúmeras esferas prateadas e brilhantes que nos lembram a cobertura de bolos de aniversários infantis. Em Bandolim, o projeto de escrita biografemática também é 


\section{Criação \&}

seguido. Além de cruzamentos intertextuais com as leituras sobre a obra de Barthes em poemas como "Há pessoas que perdem a vida por não quererem largar um/ chapéu-de-chuva. Valéry escreveu isto, li em Barthes" (LOPES, 2016a, p. 33), o livro arquiteta-se em uma escrita poética por meio de incidentes remissivos, também, à infância. Na capa do livro, há um desenho - tipicamente infantilizado - em que se visualiza uma espécie de círculo/sol repleto de raios/hastes. Tais hastes se conectam a outros círculos que, também, apresentam outras tantas hastes ad infinituum. Vale ressaltar, também, o livro Estar em casa, publicado em 2018, cuja capa talvez seja, visualmente, a que mais se adere às reminiscências do universo infantil. Nela, é focalizado um ambiente íntimo em que se destacam, no primeiro plano, brinquedos de cores variadas e de tamanhos multiformes. Em contraste às cores vivas desses objetos, percebe-se a ambientação ao fundo escurecida e a luminosidade valoriza a contemplação de bonecos, de ursos de pelúcia, artefatos de bonecas e miniaturas que lembram réplicas de objetos e utensílios do lar, tais como bules, xícaras, pires e outros bibelôs. Já em sua publicação mais recente, Dias e Dias, de 2020, há uma fotografia da poeta ainda bebê nos braços de sua mãe, fotografia, essa, que já havia sido inserida no livro Bandolim.

Nessas obras, os poemas são feitos a partir de pequenos incidentes/encontros de leituras diversas bem como de textos profundamente marcados pelo desejo da escritura: a poeta passa a escrever sua própria Vita nova por meio de lampejos romanescos, cuja base são os fragmentos rememorativos:

\section{Plásticos}

Nos anos 60, havia na Rua de Arroios uma loja que só vendia plásticos. Baldes, alguidares, tigelas. Muitas cores. Nos anos 90, vi uma exposição do Xana, ao pé do Instituto Britânico, que me fez lembrar muito esta loja da minha infância.

(LOPES, 2015, p. 14)

Sobretudo no livro Manhã, as sensações gustativas e auditivas são mais evidentes nos poemas-fragmentos. Para se referir a esses prazeres da escritura que levam a poeta a ler e a escrever incessantemente, Adília se vale de uma linguagem poética discursiva: o biografema registra momentos em que sempre se está a fazer algo, o que nos faz lembrar dos escritos barthesianos como pura essência do romanesco. Como forma de ilustrar essa escrita fragmentária e permeada de encontros diversos, trazemos cenas de escrita da poesia de Adília nas quais as sensações gustativas são rememoradas por meio de lembranças do gosto de 


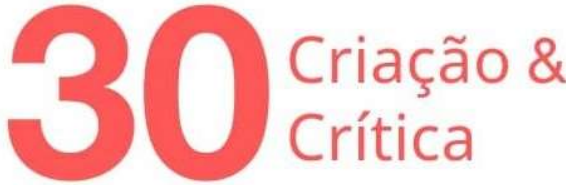

"couscous", de "lentinhas" e de "crepes de cassis", de forma semelhante a que Barthes tratou em fragmentos de $R B$ por $R B$. Sequencialmente, para que sejam aproximadas as formas de escrita por meio de incidentes, nos valemos da transposição das páginas 36 e 37 de $R B$ por $R B$ :

Figura 3 - Páginas 20 e 21 do livro Manhã

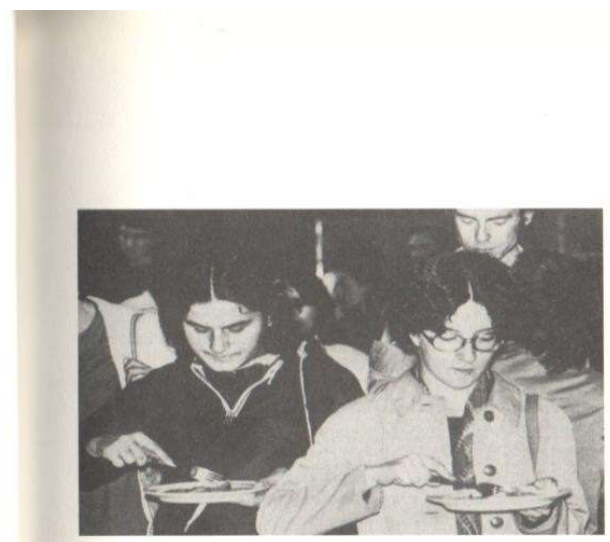

Fonte: LOPES, 2015. 


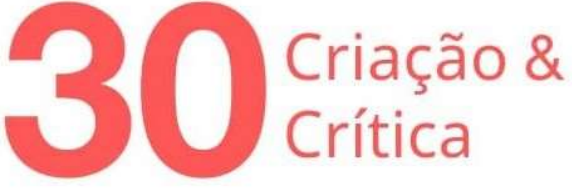

Figura 4 - Páginas 36 e 37 do livro Roland Barthes por Roland Barthes

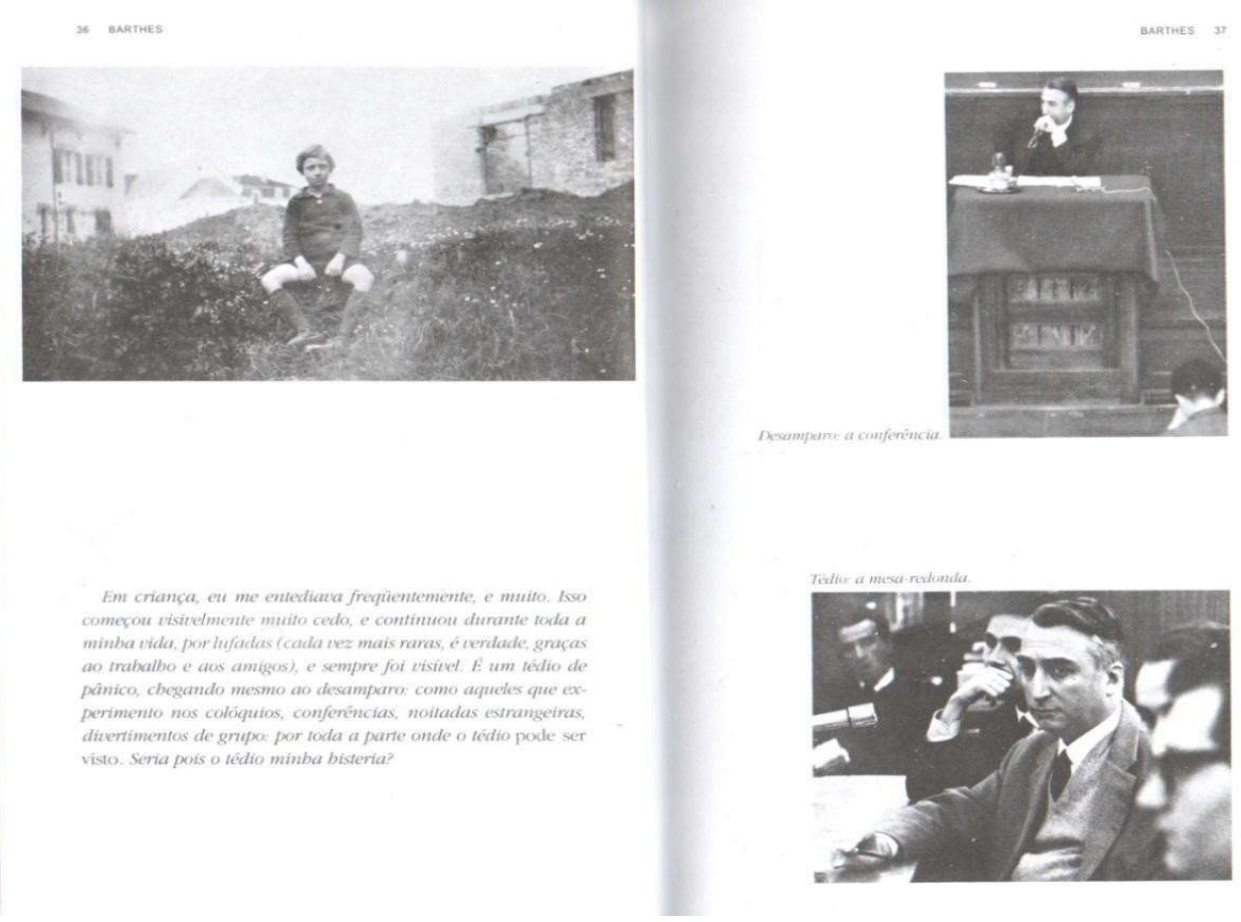

Fonte: BARTHES, 2003.

A construção do sujeito por meio da escrita e por meio das imagens, tanto em Barthes quanto em Adília, é semelhante em muitos aspectos. Nota-se como as fotografias participam dessa curadoria de se lidar com o imaginário e de instalar o biografema ao se "expor" imagens do universo acadêmico em que o "tédio" ou o "desamparo" tomam conta do corpo de Barthes. Em Adília, a fotografia registra o insignificante/irrelevante ato de comer lentilhas que a fez, por meio da gustação, criar um novo incidente. De fato, nessas duas passagens existe um notável jogo com $R B$ por $R B$ por parte de Adília. Ambos, na tentativa de apreender momentos, criam fragmentos que podem ser lidos como puros acontecimentos. No caso específico de Adília, os aspectos da vida da poeta, agora ficcionalizados, servem de subsídio para a exemplificação do prazer da escrita textual: "O intertexto compreende não apenas textos delicadamente escolhidos, secretamente amados, livres, discretos, generosos, mas também textos comuns triunfantes. Você também pode ser o texto arrogante de um outro texto". (BARTHES, 2003, p. 60). Outro poema intrigante do livro Manhã, que também trata das sensações do corpo, é o "Dansar". Ao lado desse poema, Adília insere uma fotografia sua, com 6 meses de idade: 


\section{Criação \&}

\section{DANSAR}

Desde que comecei a dansar escrevo dansar com s com a Sophia. Danso na minha cozinha descalça. Danso sozinha para os gatos. Gosto de dansar sem música o tempo que a ampulheta do meu Avô Raul mede: 10 minutos. Posso virar a ampulheta ao contrário e dansar mais 10 minutos. Posso dansar assim até o infinito. Tenho diabetes tipo 2, devo dansar por dia 30 minutos. Também ponho a caixa de música a tocar e danso. É a caixa de música que minha mãe me trouxe do aeroporto de Frankfurt, no final dos anos 60, quando voltou de um congresso de Botânica em Darmstadt. Esta caixa de música é um abeto com um casamento de passarinhos à volta. É cor-de-rosa e verde. Há um romance de Stendhal que se chama Le rose et vert. Ainda não li. Mas tenho o livro. Posso ler. Gosto de pensar nessas coisas enquanto danso. Enquanto danso, penso. Penso e giro. De girar e de gerir. Enquanto danso, raciocino e raciocino melhor. Enquanto danso, rezo pela paz. Enquanto danso, descanso. O meu pâncreas melhora. Só coisas boas. Tenho uma cassette de rock jugoslavo que a minha intéprete em Sarajevo, a Amra, gravou para mim. Estive em Saravejo em Maio de 1991 num encontro de poetas. Também danso rock. Dansar é leve e intenso como diz a Tereza Amado.

$4 / 8 / 14$

(LOPES, 2015, p. 77-78) 


\section{Criação \&}

Figura 5 - Páginas 76 e 77 do livro Manhã

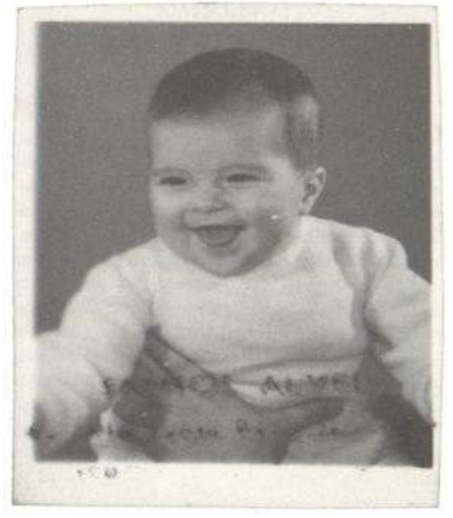

DANSAR

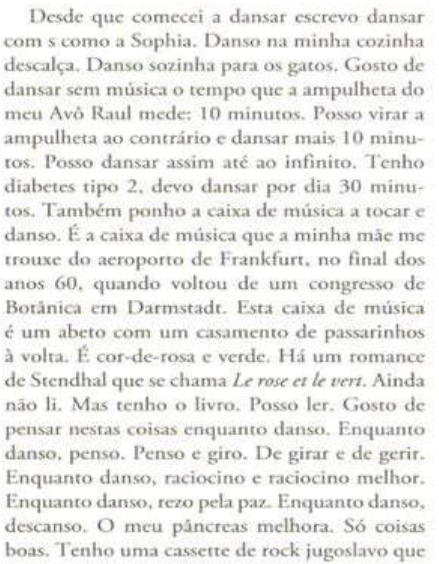

Fonte: LOPES, 2015

Trata-se de um biografema que inverte posições binárias. Adília aniquila a possibilidade de construção autoral total ou, pelo menos, autobiográfica. Ora, ao se valer de uma fotografia de um bebê, que sensações a poeta poderia rememorar? Além disso, há inúmeras artimanhas poéticas que desestabilizam o tom narrativo autobiográfico. A dicção em prosa narra eventualidades do cotidiano da poeta ao lado dos seus gatos. Passado, presente e futuro se entremeiam no poema e ao recordar sensações - por meio da audição e da visão - esse espectro apresenta-se, ao mesmo tempo, infantil e adulto: "Enquanto danso, descanso./ O meu pâncreas melhora. Só coisas boas." Além disso, os versos ironizam a ideia do sujeito cartesiano pautado no penso, logo existo: "Enquanto/ danso, penso. Penso e giro. De girar e de gerir./ Enquanto danso, raciocino e raciocino melhor./ (LOPES, 2015, p. 77). Em via oposta à da criação de uma identidade una e sólida, nota-se a transgressão de normas e espaços, até então, rígidos. Nesse e outros poemas dessas últimas obras, constatase que a poesia de Adília marca o lugar em que o sujeito se produz com risco: "[...] um lugar onde o sujeito se arrisca numa situação de crítica radical, e não o produto acabado de um sujeito pleno" (PERRONE-MOISÉS, 2005, p. 49). O poema "Minsk" também forja supostas memórias da infância dessa poeta que se mesclam à consciência da poeta na idade adulta. Os resultados dessas mélanges autênticas, que desapropriam noções e textualidades, leem-se abaixo: 
MINSK

Quando eu tinha 11 anos, li um texto no meu livro de leitura de Português do Ciclo Preparatório de que gostei muito. Já não me lembro do nome do autor e já não tenho esse livro. Era o caso de uma pessoa a quem tinham oferecido um periquito, acho que o pássaro era um periquito. A pessoa não sabia que nome dar ao periquito. Então abriu um mapa do mundo em cima de uma mesa e deixou o periquito andar em cima do mapa. O periquito parou em Minsk e ficou a chamar-se Minsk.

A minha professora de português Maria Crisanta Santos gostava muito das minhas redacções, dava-me notas muito altas. Dizia, quando eu tinha 11 anos, que eu havia de ser uma escritora conhecida. Emprestou-me Platero e eu Juan Ramón Jiménez. Adorei esse livro, ainda hoje é para mim um livro de cabeceira.

Aos 12 anos, trouxe da biblioteca da escola para casa O músico cego de Vladimiro Korolenko. Também foi um livro que adorei. Também é para mim um livro de cabeceira. Emma Goldman, a anarquista lituana que dizia: «Se eu não puder dansar, esta não é minha revolução», foi contemporânea de Vladimiro Korolenko, visitou Korolenko na Rússia em 1920 (cf. Clara Queiroz, Se não puder dançar, esta não é a minha revolução: aspectos da vida de Emma Goldman, Assírio \& Alvim, Lisboa 2008, p. 200).

Até os 12 anos, não tinha encontrado na literatura portuguesa textos de que eu gostasse tanto e que tivessem tanto a ver co-

migo como Platero e eu e O músico cego. Ainda não encontrei. Continuo a mesma. Só me lembro das cantigas de amigo.

(LOPES, 2016a, p. 56-57)

Por meio da leitura dos poemas dos últimos livros da poeta, se fizermos um estudo panorâmico, percebemos que eles se valem da noção de texto como lugar de perda, "de fading do sujeito, produção livre e efêmera de sentidos provisórios, lugar de prazer, lugar de entrelaçamento" (PERRONE-MOISÉS, 2005, p. 51). Assim como o livro Manhã, Bandolim (2016a) é outra criação da poeta que está repleta de poemas nos quais se registram sensações do corpo ficcionalizado da poeta na infância. Nesse livro, bem como na obra que antecede, a rememoração aos prazeres e às memórias infanto-juvenis são marcadas sensações gustativas. Os dois poemas a seguir registram os prazeres presentes nesses incidentes: 


\section{Criação \&}

A minha mãe deixou-me sempre comer todos os bolos e todos os chocolates que me apeteceu, deixou-me sempre ler todos os livros e ver todos os filmes que me apeteceu. Nunca tive de andar a fazer coisas à socapa. Fui uma grande sortuda. Viva a liberdade!

(LOPES, 2016a, p. 42)

JIRIPITI

Quando estava doente em criança, a minha mãe dava-me às vezes Fenergan e Diegese com uma colher de chá ou de café.

São uns remédios que sabem muito bem. A minha mãe ainda diziame

que mais tarde eu havia de gostar do jiripiti.

(LOPES, 2016a, p. 39)

Os sentidos, ou melhor, as sensações advindas desses corpos escritos são, por sua vez, assim como os atos de leitura, plurais e dependem das circunstâncias de leitura e dos momentos de pausa que leitor tem para com o poema. Os jogos de referenciais na escrita adiliana fazem com que o poema funcione como uma espécie de máquina-leitora-apropriativa em continuum que exige o "leitor total" a que Barthes se refere: aquele leitor que, ao ler, escreve textos, dispersa-se em possibilidades plurais de sentido que disseminarão no prazer e no desejo da escritura. Por fim, assim como Barthes, Adília possibilita aos leitores da sua própria textualidade a aventura de ler de outro lugar, dando-lhes liberdade de sentir o gozo individualizado. Nesse sentido, essa leitora de Barthes almeja que seu leitor, também, desenvolva "[...] o desejo que o escritor teve de escrever, ou ainda: [. .] o desejo que o autor teve do leitor enquanto escrevia, [...] oame-me que está em toda escritura” (BARTHES, 2004a, p. 39).

\section{Referências}

BARTHES, R. O prazer do texto. Tradução J. Guinsburg. São Paulo: Perspectiva, 2010.

BARTHES, R. Sobre Racine. Tradução Ivone Castilho Benedetti. São Paulo: Editora WF Martins Fontes, 2008.

BARTHES, R. Crítica e verdade. Tradução de Leyla Perrone-Moisés. São Paulo: Perspectiva, 2007.

BARTHES, R. A preparação do romance I: da vida à obra, Tradução Leyla PerroneMoisés, São Paulo, Martins Fontes, 2005a.

BARTHES, R. Sade, Fourier, Loyola. Tradução de Mário Laranjeira. São Paulo: Martins Fontes, 2005b. 


\section{Criação \&}

BARTHES, R. "Da leitura”. In: O rumor da língua. Tradução Mário Laranjeira, São Paulo: Martins Fontes, 2004a, p. 30-42.

BARTHES, R. Incidentes. Tradução Mário Laranjeira. São Paulo: Martins Fontes, 2004b.

BARTHES, R. O grão da voz: entrevistas - 1962-1980. Tradução Mário Laranjeira. São Paulo: Martins Fontes, 2004c.

BARTHES, R. Roland Barthes por Roland Barthes. Tradução de Leyla PerroneMoisés. São Paulo: Estação Liberdade, 2003.

BARTHES, R. O grau zero da escrita: seguido de novos ensaios críticos. Tradução Mário Laranjeira. São Paulo: Martins Fontes, 2000.

BARTHES, R. S/Z. Tradução Maria de Santa Cruz e Ana Mafalda Leite. Lisboa: Edições 70, 1999.

COSTA, L. B. Estratégias biográficas: biografemas com Barthes, Deleuze, Nietzsche e Henry Miller. Porto Alegre: Sulina, 2011.

FOUCAULT, M. O que é um autor? Tradução António Fernando Cascais. Lisboa: Vega, 2006.

LOPES, A. Dias e Dias. Porto: Assírio \& Alvim, 2020.

LOPES, A. Estar em casa. Porto: Assírio \& Alvim, 2018.

LOPES, A. Bandolim. Porto: Assírio \& Alvim, $2016 a$.

LOPES, A. Z/S. Lisboa: Averno, 2016b.

LOPES, A. Manhã. Porto: Assírio \& Alvim, 2015.

LOPES, A. Dobra: poesia reunida (1983-2014). Porto: Assírio \& Alvim, 2014.

MARTELO, R. M. "Memórias da infância na poesia de Adília Lopes (Lirismo e

Autobiografia)". Telhados de vidro, Lisboa, n. 22, p. 257-273, 2017.

PERLOFF, M. O gênio não original: poesia por outros meios no novo século. Tradução Adriano Scandolara. Belo Horizonte: Editora UFMG, 2013.

PERRONE-MOISÉS, L. Texto, crítica, escritura. São Paulo: Martins Fontes, 2005.

OLIVEIRA, P. "Incômodos 'Incidents'”. Revista Criação \& Crítica, São Paulo, n. 4, 171-181, 2010.

PINO, C. A. "De um corpo para outro. Roland Barthes e a biografemática". Revista Criação \& Crítica, São Paulo, n. 17, 15-29, 2016.

PINO, C. A. Roland Barthes: a aventura do romance. Rio de Janeiro: 7 Letras, 2015. VILLA-FORTE, L. Escrever sem escrever: literatura e apropriação no século XXI. Rio de Janeiro: Ed. PUC-Rio, 2019.

WAHL, F. Nota do editor francês. In: BARTHES, R. Incidentes. Tradução Mário Laranjeira. São Paulo: Martins Fontes, 2004, p. vii-xi.

Recebido em: 15/04/2021 Aceito em: 22/06/2021

Referência eletrônica: SALES, Paulo Alberto da Silva. Incidentes Poéticos de Adília Lopes, leitora de Barthes. Criação \& Crítica, n. 30, p., set. 2021. Disponível em: $<$ http://revistas.usp.br/criacaoecritica>. Acesso em: dd mmm. aaaa. 